\title{
A CRENÇA DE AUTOEFICÁCIA DOS FORMANDOS DE UM CURSO DE PEDAGOGIA EM RELAÇÃO AO EXERCÍCIO PROFISSIONAL
}

\author{
Paula Mariza Zedu Alliprandini ${ }^{1}$ \\ Diana Aparecida de Souza ${ }^{2}$
}

Resumo: Este trabalho está embasado na Teoria Social Cognitiva, mais especificamente referente ao constructo das crenças de autoeficácia, definida como o julgamento das pessoas sobre suas capacidades para organizar e executar cursos de ação necessários para alcançar certos tipos de desempenhos. Teve como objetivo geral analisar a crença de autoeficácia dos acadêmicos do último ano do curso de Pedagogia de uma Instituição Pública em relação ao exercício profissional e como objetivos específicos comparar o nível de autoeficácia dos acadêmicos em relação ao exercício profissional e do período de oferta do curso e analisar os itens Decisão de carreira e Autoeficácia Profissional dos acadêmicos separadamente. Participaram da pesquisa 76 acadêmicos formandos, matriculados nos períodos matutino e noturno, de uma Universidade Pública. A coleta de dados foi realizada por meio da aplicação de um questionário sóciodemográfico e uma escala do tipo Likert, de cinco pontos, contendo questões referentes à Decisão de Carreira e Autoeficácia Profissional. No geral, a análise dos dados evidenciou que os acadêmicos apresentaram um nível de crença moderado. Porém, aqueles que participaram de atividades acadêmicas complementares, bem como atuavam na área de Educação, apresentaram maiores escores em relação aos demais. Provavelmente, a participação nestas atividades tenha promovido uma experiência de domínio positiva, a partir dos conhecimentos adquiridos e da relação teoria prática estabelecida. Dessa forma, ressalta-se a importância do colegiado e docentes do curso incentivarem a participação dos alunos nestas atividades, de forma a levar com que os futuros professores desenvolvam uma crença positiva em relação ao exercício profissional.

Palavras-chave: Teoria Social Cognitiva. Crença de autoeficácia. Ensino Superior. Pedagogia. Exercício profissional.

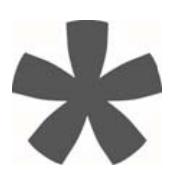

${ }^{1}$ Doutora em Psicobiologia pela FFCLRP/USP. Pós-Doutora em Psicologia pela "Cornell University", Ithaca, USA. Docente do Departamento de Educação e do Programa de Pós-Graduação em Educação da Universidade Estadual de Londrina.

${ }^{2}$ Graduada em Pedagogia pela Universidade Estadual de Londrina. Professora regente junto a Prefeitura Municipal de Londrina. 


\title{
THE SELF-EFFICACY BELIEF OF TRAINEES FROM A PEDAGOGY COURSE REGARDING PROFESSIONAL PRACTICE
}

\begin{abstract}
This work is based on the Social Cognitive Theory, more specifically regarding the construct of self-efficacy beliefs, defined as the judgment of people regarding their capacities to organize and execute necessary courses of action to reach some kinds of performance. Its general objective was analyzing the self-efficacy belief of students from the last year of the Education Course from a Public Institution regarding the professional practice, and its specific objectives were comparing the level of self-efficacy of the students regarding professional practice and the period when the course was offered and analyzing the items Career Decision and Professional Self-Efficacy of the students in separate. Seventy-six academic trainees, registered in both morning and evening periods from a Public University, took part in the research. Data collection was performed by means of a sociodemographic questionnaire. This is a Likert type scale, of five points, having questions regarding Career Decision and Self-efficacy Belief. In general, data analysis evidenced that the trainees had a moderate level of belief. However, both the ones who took part in complementary academic activities and who worked in Education area had higher scores regarding the others. Probably, the participation in those activities promoted a positive domain experience, from the acquired knowledge and the established theory practice relationship. Thus, it is highlighted the importance of the collegiality and professors of the course to encourage the participation of students in those activities, to lead future teachers to develop a positive belief regarding professional practice.
\end{abstract}

Keywords: Social Cognitive Theory. Self-efficacy Belief. Higher Education. Pedagogy. Professional Practice.

\section{LA CREENCIA DE AUTOEFICÁCIA DE LOS FORMANDOS DE UN CURSO DE PEDAGOGÍA EN RELACIÓN AI EJERCICIO PROFESIONAL}

Resumen: Este trabajo tiene como base la Teoría Social Cognitiva, más concretamente referente al constructo de las creencias de autoeficacia, definida como el juicio de las personas sobre sus capacidades para organizar y ejecutar cursos de acción necesarios para alcanzar ciertos tipos de desempeños. Tuvo como objetivo general analizar la creencia de autoeficacia de los académicos del último año del curso de Pedagogía de una Institución Pública en relación al ejercicio profesional; como objetivos específicos comparar el nivel de autoeficacia de los académicos en relación al ejercicio profesional y al período de oferta del curso, con un análisis de los siguientes ítens separadamente: Decisión de carrera y Autoeficacia Profesional de los académicos. Participaron de la investigación 76 académicos graduados, de los periodos matutino y nocturno, de una Universidad Pública. La recolección de datos fue realizada por medio de la aplicación de un cuestionario sóciodemográfico y una escala del tipo Likert, de cinco puntos, conteniendo cuestiones referentes a la Decisión de Carrera y Autoeficacia Profesional. En general, el análisis de los datos dejó evidente que los académicos presentaron un nivel de creencia moderado. Sin embargo, aquellos que participaron de actividades académicas complementarias, como también actuaban en el área de Educación, presentaron mayores escores en relación a los demás. Probablemente, la participación en estas actividades haya promovido una experiencia de dominio positiva, a partir de los conocimientos adquiridos y de la relación teoría práctica establecida. De esa forma, se resalta la importancia de que el colegiado y los docentes del curso incentiven la participación de los alumnos en estas actividades, de modo que los futuros profesores puedan desarrollar una creencia positiva en relación al ejercicio profesional.

Palabras clave: Teoría Social Cognitiva. Creencia de autoeficacia. Enseñanza Superior. Pedagogía. Ejercicio profesional. 


\section{Introdução}

Por meio de um Curso Superior, o acadêmico visa sua formação, a aquisição de novos conhecimentos e, por conseguinte, busca a realização e satisfação pessoal e profissional. Deste modo, a Universidade é considerada como oportunidade para o ingresso no mercado de trabalho, proporcionando ainda, além de novos conhecimentos, novas perspectivas sobre a profissão escolhida, aquisição de valores e amadurecimento pessoal que de fato impulsione profissionalmente o acadêmico (MOGNON; SANTOS, 2014).

A proposta deste trabalho está embasada na Teoria Social Cognitiva proposta por Bandura (1986 apud PAJARES; OLAZ, 2008), com ênfase sobre as crenças de autoeficácia. De acordo com Bandura (1986 apud PAJARES; OLAZ, 2008), a crença de autoeficácia se refere às percepções que os indivíduos têm de suas próprias capacidades, as quais podem influenciar neste processo, de formação e atuação, assim como coloca Bandura (2008, p. 46), “[...] as expectativas de eficácia e de resultados das pessoas influenciam a maneira como elas agem, e os efeitos ambientais criados por suas ações, por sua vez, alteram suas expectativas."

Considerando a sociedade contemporânea em meio a tantos desafios que permeiam o campo educacional; “[...] carga horária excessiva, turmas numerosas, baixos salários, desrespeito, indisciplina, entre outros" como destaca laochite et al. (2011, p. 827); o objetivo geral da presente pesquisa foi analisar a crença de autoeficácia dos acadêmicos formandos do curso de Pedagogia de uma Instituição Pública em relação ao exercício profissional e teve como objetivos específicos, comparar o nível de autoeficácia dos acadêmicos que já atuavam na área de educação e os que ainda não estavam atuando profissionalmente neste campo, comparar os níveis de crença de autoeficácia dos acadêmicos matriculados no período matutino e noturno e, por fim, analisar separadamente os níveis de Decisão de Carreira e Autoeficácia Profissional dos participantes.

A respeito da formação docente e autoeficácia, a literatura vem indicando que, professores com elevado nível de autoeficácia apresentam-se mais motivados e acabam gerando motivação também aos seus alunos acarretando mudanças no comportamento dos mesmos (AZZI; POLYDORO; BZUNECK, 2006; BZUNECK, 2001; ROSS, 1995 apud SILVA; 
IAOCHITE; AZZI, 2010, p. 942). “As crenças de auto-eficácia seriam preditoras da ação do professor e, conseqüentemente, fator de extrema relevância na aprendizagem do aluno", conforme ressalta Rocha (2009, p. 76).

Dessa forma, a presente pesquisa poderá subsidiar reflexões sobre o processo de formação inicial dos pedagogos, ao que se refere à ação educativa, em especial em relação ao senso de autoeficácia dos acadêmicos em relação ao exercício da profissão.

\section{Teoria Social Cognitiva e as Crenças De Autoeficácia}

A Teoria Social Cognitiva é resultado de estudos contemporâneos, que tem como precursor Albert Bandura. Surgiu em meados de 1960, a princípio denominada Teoria da Aprendizagem Social, na qual em 1970, o mesmo percebeu que faltava algo fundamental nas demais teorias do momento e em sua própria teoria referente à aprendizagem social. Sendo assim, em 1977, com a Publicação de Self-efficacy: toward a unifying theory of behavioral change, Bandura descreve que os indivíduos criam e desenvolvem percepções pessoais sobre si mesmos, servindo como mecanismos de persistência e de controle sobre ambiente em que vivem. Desse modo, em 1986, Bandura modificou e adaptou o nome de sua teoria para a atual Teoria Social Cognitiva, destacando a importante função que a cognição desempenha na capacidade das pessoas em construir a realidade, autorregularem-se, decifrar informações e realizar comportamentos (PAJARES; OLAZ, 2008, p. 97).

A base da concepção de Bandura (1986 apud PAJARES; OLAZ, 2008, p. 98) respalda-se no determinismo recíproco, na qual este consiste em "fatores pessoais na forma de cognições, afetos e eventos biológicos, influências comportamentais e ambientais que criam interações que resultam em uma reciprocidade triádica". Ao passo bidirecionalmente" (BANDURA; JOURDEN, 1991 apud AZZI; POLYDORO, 2006, p. 17) de modo que estes fatores interferem no funcionamento humano.

A Teoria Social Cognitiva ressalta, por meio do conceito de agência humana, o pressuposto de que "o indivíduo influencia o próprio comportamento e as circunstâncias de sua vida, pois não é apenas alvo das influências do meio, mas também age sobre ele e produz influências que o modificam" (BANDURA, 2001 apud FONTES; AZZI, 2012, p. 106). 
Entre os fatores pessoais, segundo Olaz e Pajares (2008, p. 99) "os indivíduos possuem autocrenças que Ihes possibilitam exercer certo grau de controle sobre seus pensamentos, sentimentos e ações", de modo que estas podem influenciar em seu comportamento. Rocha $(2009$, p. 21) sintetiza que "o poder de iniciar ações para alcançar determinados resultados é a chave da agência pessoal."

Segundo Pajares e Olaz (2008, p. 99), “os indivíduos são produtos e produtores de seus ambientes e sistemas sociais", uma vez que este pode agir sobre o ambiente e ser alterado através do mesmo, sendo contrário às teorias do funcionamento humano que extrapolam o papel dos fatores ambientais no comportamento humano e desenvolvimento da aprendizagem.

Um dos pensamentos que afetam o funcionamento humano são as crenças de autoeficácia, na qual são definidas como os "julgamentos das pessoas em suas capacidades para organizar e executar cursos de ação necessários para alcançar certos tipos de desempenhos, ou seja, são as percepções que os indivíduos têm sobre suas próprias capacidades" (PAJARES; OLAZ, 2008, p. 100).

Segundo Bandura (1997 apud FONTES; AZZI, 2012, p. 107), as crenças de autoeficácia "têm papel crucial para a determinação do comportamento humano". Além disso, a autoeficácia ainda é tida como um constructo pessoal e social, considerando que os indivíduos agem de maneira coletiva e individualmente (PAJARES; OLAZ, 2008).

Em relação ao funcionamento humano, a crença de autoeficácia desempenha um papel importante que, segundo Bandura (1997 apud PAJARES; OLAZ, 2008, p. 102) se refere ao fato de que o "nível de motivação, os estados afetivos e as ações das pessoas baseiam-se mais no que elas acreditam do que no que é objetivamente verdadeiro". Tendo em vista que a autoeficácia não se refere ao fato dos sujeitos possuírem ou não habilidades, conhecimentos, capacidades, mas sim do indivíduo acreditar que as possui, e que é capaz de realizar determinada ação (BZUNECK, 2001), torna-se assim um forte mecanismo na agência pessoal; (BANDURA, 1986, 1997 apud VIEIRA; COIMBRA, 2006) afetando assim, as escolhas, a persistência, o desempenho e desafios e serem enfrentados e consequentemente, a vida do indivíduo.

As crenças de autoeficácia, segundo Rocha (2009), têm uma importância fundamental para o funcionamento humano, atuando como regulador e ativador do mesmo, através de 
quatro processos no qual operam em conjuntos ou isolado, sendo estes os processos cognitivos, processos motivacionais, processos afetivos e processos seletivos.

Portanto, os efeitos das crenças de autoeficácia nos processos cognitivos referem-se ao estabelecimento de metas e objetivos, por meio de pensamentos antecipatórios, que regulam as ações, direcionamento e perseverança sobre as tarefas, conforme o anseio que destina para a obtenção de sucesso.

Vários trabalhos têm sido realizados, como por exemplo, relacionados à: autoeficácia e formação superior (GUERREIRO-CASANOVA; POLYDORO, 2011), área de Educação Física (FERREIRA, 2008), eficácia docente (SILVA; IAOCHITE; AZZI, 2010), autoeficácia e desempenho em Matemática (SOUZA; BRITO, 2008) e ainda a relação da autoeficácia na transição para o trabalho, presentes no capítulo proposto por Vieira e Coimbra (2006), pelos quais percebe-se que as crenças de autoeficácia estão presentes nas relações sociais, influenciando as ações e comportamentos das pessoas.

Considerando as crenças de autoeficácia como um constructo essencial da Teoria Social Cognitiva, que resulta em implicações no comportamento, no funcionamento, nas ações humanas a partir da confiança na capacidade para realizações, estas constituem cognitivamente informações por meio de quatro fatores, conforme Pajares e Olaz (2008): Experiência de Domínio, Experiência Vicária, Persuasão Social e por último, Estados Somáticos e Emocionais.

De modo que tida como a fonte mais influente, a Experiência de Domínio refere-se à interpretação de resultados oriundos das ações das pessoas, na qual estas usam tais interpretações para desenvolver suas crenças a respeito de suas capacidades frente a realização de atividades atuando conforme as crenças produzidas. Sendo que os resultados interpretados como bons, aumentam a autoeficácia, e os interpretados como ruins, as diminuem (PAJARES; OLAZ, 2008).

As pessoas formam ainda as crenças de autoeficácia por meio da Experiência Vicária, que implica na observação de ações e resultados de outras pessoas, principalmente quando os sujeitos possuem dúvidas sobre suas capacidades ou não possuem experiência, enfatizando os efeitos do processo de modelação, descrito na Teoria Social Cognitiva proposta por Albert Bandura. Ressaltando ainda que terá maior influência, se a pessoa observada obter significado, admiração do outro sujeito. No entanto, estas crenças podem 
ser aumentadas por outro fator, oriundo das persuasões sociais que recebem de outras pessoas, de modo que estas persuasões, em geral verbais, devem desenvolver as crenças das pessoas em suas próprias capacidades. Porém estas persuasões podem ser positivas, reforçando as crenças de autoeficácia ou negativas, enfraquecendo e diminuindo-as, conforme relata Pajares e Olaz (2008).

Em relação aos Estados Somáticos e Emocionais, fatores como ansiedade, estresse, cansaço, condições de humor, segundo Pajares e Olaz (2008, p. 105) "proporcionam informações sobre as crenças de auto-eficácia. As pessoas podem avaliar o seu grau de confiança por seu estado fisiológico enquanto passam em uma determinada ação". Ou seja, afetam a realização e a confiança do sujeito para realizar determinadas atividades, uma vez que os indivíduos confiantes preveem resultados sociais bem-sucedidos, já os estudantes que duvidam de suas habilidades, preveem que serão ridicularizados e rejeitados antes mesmo do contato social.

Entretanto "o ambiente influencia o comportamento, mas em parte este é criado pela própria pessoa; por meio de suas ações, as pessoas desempenham um papel na criação do meio social e de outras circunstâncias que surgem." (BANDURA, 2008, p. 44). Resultando assim no comportamento recíproco do indivíduo, como levantado acima, de modo que envolve fatores comportamentais, cognitivos e ambientais. Guerreiro-Casanova e Polydoro (2011, p. 52) destacam que "as crenças de autoeficácia são constituídas ao longo da vida." Sendo assim, é essencial ressaltar esses fatores no processo de aquisição de conhecimento do indivíduo e sua formação.

\section{Formação Docente e Autoeficácia}

Considerando que a educação está se tornando cada vez mais complexa, o mesmo acontece com a profissão docente; na qual tal complexidade é oriunda das mudanças científicas, sociais, e educativas (IMBERNÓN, 2002). Dessa forma, é fundamental que a formação docente promova conhecimentos, habilidades e um bom desempenho na prática educativa, conforme apontado por Ghedin, Leite e Almeida (2008, p. 31):

É preciso assegurar que a formação de professores possibilite ao profissional docente saber lidar com o processo formativo dos alunos em suas várias dimensões, além da cognitiva, englobando a dimensão afetiva, da educação dos sentidos, da estética, da ética e dos valores emocionais. 
Segundo Azzi, Polydoro e Bzuneck (2006), as crenças de autoeficácia têm sido exploradas no campo educativo, entre alunos, professores, coordenadores pedagógicos, diretores, equipes, até mesmo relacionada a escola como um todo. Estas podem contribuir na prática docente, ao passo que a autoeficácia docente é "entendida como a crença na própria capacidade de exercer efeito produtivo e relevante na quantidade e qualidade do envolvimento e aprendizagem dos alunos, considerando a diversidade destes." (BANDURA, 1977, BZUNECK; GUIMARÃES, 2003, TSCHANNEN-MORAN; WOOLFOOLK HOY, 2001 apud AZZI; POLYDORO; BZUNECK 2006, p. 151).

No entanto, as crenças de autoeficácia docente são formadas a partir das quatro fontes de informação conforme já descritas acima e destacadas aqui:

[...] experiência direta (experiências de êxito em tarefas) anteriores, experiência vicária (observação de outras pessoas com êxito em situações similares), persuasão social (influências sociais de convencimento) e estado físico e emocional (fornecedor de critério para julgamento da capacidade, força e vulnerabilidade). (BANDURA, 2004 apud AZZI; POLYDORO; BZUNECK, 2006, p. 153).

Deste modo, a autoeficácia do professor pode contribuir nas implicações de sua prática educativa, em relação à maneira de ensinar do mesmo, em suas ações, de promover a aprendizagem e a motivação dos alunos, inclusive contribuir para o desenvolvimento das crenças de autoeficácia do mesmo, bem como as estratégias usadas, a competência para abordar e trabalhar conteúdos, referentes ao domínio da sala, e ainda estratégias que possibilitem maior insistência e perseverança quanto às situações adversas. Segundo Azzi, Polidoro e Bzuneck (2006), os professores devem acreditar na transformação dos alunos, e possivelmente na transformação social.

Estudos realizados no âmbito internacional revelam, segundo Rocha (2009, p. 46) que, "a auto-eficácia do professor não somente se relaciona com resultados dos alunos quanto ao seu rendimento, motivação e autoeficácia, mas também está vinculada aos comportamentos que os alunos manifestam na aula."

É possível associar que a crença de autoeficácia para a formação docente torna-se preponderante para a ação educativa, partindo do pressuposto de que estas podem influenciar na maneira de pensar dos sujeitos, o quanto é persistente, frente aos desafios, refletindo no comportamento e na realização de ações na vida dos indivíduos (PAJARES; OLAZ, 2008). 
Sendo assim, faz-se necessário que, na formação acadêmica, os futuros docentes, estejam com suas crenças de autoeficácia com um bom nível positivo, para que possam ser transformadores da realidade, e se sintam confiantes em suas capacidades, frente ao processo de ensino. Conforme Gibbs (2002 apud ROCHA, 2009, p. 40) aborda que:

[...] professores com fortes crenças de auto-eficácia, além de persistirem mais em situações de fracasso, melhorarem a realização de seus alunos e os manterem mais motivados, arriscam-se mais em novas abordagens de ensino, são mais propensos à satisfação com o trabalho, demonstram mais compromisso e apresentam baixos índices de absenteísmo.

Rocha $(2009$, p.76) ressalta que a formação docente deve incumbir este aporte teórico da autoeficácia docente, como "possibilidade do desenvolvimento de um professor que confie na possibilidade de lidar com os recursos próprios disponíveis para enfrentar os desafios inerentes à docência, focado na solução de problemas e que assuma responsabilidades pelo próprio crescimento."

Goya, Bzuneck e Guimarães (2008 apud GLASER, 2010, p. 10) concluem que:

[...] toda instituição escolar, e pode-se incluir aí a Universidade, deve exercer a dupla função de propiciar que os alunos desenvolvam tanto as reais competências que o mundo moderno exige, como também as crenças de que possuem tais competências, o que lhes confere força motivacional para aprenderem e continuarem aprendendo, para terem êxito nestes novos tempos.

Este trabalho está focado principalmente na crença de autoeficácia dos acadêmicos na formação superior. Nesse sentido, Dias e Azevedo (2001 apud GUERREIRO-CASANOVA; POLYDORO 2011) afirmam que a autoeficácia na formação superior constitui-se como um decisivo para o rendimento acadêmico. Esta implica em oferecer subsídios, para que o graduando se sinta mais eficaz e mais confiante para o exercício profissional. Considerando segundo Imbernón (2002, p. 15) que:

A formação assume um papel que transcende o ensino que pretende uma mera atualização científica pedagógica e didática e se transforma na possibilidade de criar espaços de participação, reflexão e formação para que as pessoas se adaptem para poder conviver com a mudança e a incerteza.

De acordo com Ourique, 2010 (apud CERUTTI et al., 2011, p. 59) "As crenças em relação às habilidades pessoais influenciam positivamente na precisão das atividades que o universitário irá exercer futuramente." 
Rocha (2009) ressalta que investigar as crenças de autoeficácia trará subsídios para a discussão a respeito da formação docente, e nesse sentido torna-se importante que as Instituições de Ensino Superior criem condições favoráveis nos cursos de licenciaturas, para que os alunos em processo de formação tenham oportunidades de reflexões sobre a percepção de suas capacidades, de modo que se sintam autoeficazes, afetando de maneira positiva seu planejamento e ação. Nesse sentido, o presente trabalho buscou investigar sobre o nível de autoeficácia dos acadêmicos formandos de um curso de Pedagogia de uma Instituição Pública Superior em relação ao exercício da docência.

\section{Metodologia}

\section{Participantes}

Um total de 76 formandos do curso de Pedagogia, pertencentes a faixa etária entre 21 e 54 anos participaram da pesquisa. Do total, 74 eram do sexo feminino e 2 do sexo masculino. Os participantes estavam distribuídos nas seguintes Turmas: Turma 1000 (26 participantes); turma 2000 (20 participantes), Turma 3000 (16 participantes) e Turma 4000 (14 participantes).

\section{Instrumentos}

Para a coleta dos dados foi aplicado um questionário contendo questões sobre a caracterização dos participantes em relação a: sexo, idade, conclusão de outro curso superior, participação em atividades acadêmicas (projetos de pesquisas/iniciação científica, disciplinas especiais, projeto de extensão e de iniciação a docência), e por último relativo ao exercício ou não de atividade profissional relacionada ou não à area de formação.

Foi também aplicada uma Escala composta por 18 itens, sendo 10 itens relativos à Autoeficácia profissional e 8 itens relativos a Decisão de Carreira, elaborada por Teixeira e Gomes (2005 apud GLASER, 2010, p. 12). Este instrumento é uma escala do tipo Likert, de cinco pontos, indicando diferentes graus de concordância com as afirmações. Para tanto, os participantes deveriam assinalar para cada questão, correspondente a sua resposta, 1Nada característico, 2- Um pouco característico, 3 - Irrelevante, 4 - Característico, 5 - Muito característico. Conforme proposto pela escala, para tabulação e análise da escala, a 
pontuação de cada item da escala varia de 1 a 5. Do total de itens, 7 questões eram afirmativas negativas, e nesse caso, os valores foram invertidos.

\section{Procedimento}

O projeto foi inicialmente aprovado pelo Comitê de Ética em Pesquisa (CEP/UEL), conforme parecer 646.213 emitido em 28/04/2014.

Antes de iniciar a coleta de dados, foram entregues aos participantes o Termo de Consentimento Livre e Esclarecido (TCLE). Portanto, participaram da pesquisa somente aqueles que concordaram em participar, mediante a assinatura do TCLE. Na sequência, foi entregue o questionário para caracterização do participante e a Escala sobre Autoeficácia profissional e Decisão de Carreira, elaborada por Teixeira e Gomes (2005 apud GLASER, 2010, p. 12). A coleta de dados foi realizada presencialmente, de forma coletiva.

\section{Resultados e Discussões}

Em relação a caracterização dos participantes, a análise evidenciou que do total de participantes (76), 74 eram do sexo feminino e 2 do sexo masculino e que a idade dos participantes variou entre 21 a 54 anos, com uma média de 26,85. Do total de participantes, 6 informaram ter cursado outra graduação.

No que concerne a participação em atividades acadêmicas, como projeto de pesquisa/iniciação científica, disciplinas especiais, projeto de extensão e iniciação a docência, verificou-se que, dos 76 participantes da pesquisa, 30,27\% (23 acadêmicos) participavam destas atividades, sendo que destes 23 acadêmicos, 86,95\% (20 acadêmicos) fizeram parte de projetos de pesquisa/iniciação científica, 4,35 \% (1 acadêmico) cursou disciplina especial, 4,35\% (1 acadêmico) participou de projeto de extensão e 1 outro acadêmico (4,35\%) teve participação em projeto de iniciação à Docência (Pibid).

Os dados evidenciaram que, dos participantes que trabalham, a maior parte exerce alguma atividade profissional relacionada à área do curso de pedagogia, mas também uma parte considerável não desenvolve nenhuma atividade profissional.

Segundo Cardoso e Sampaio (2004 apud GLASER, 2010), tornou-se uma realidade cada vez mais frequente nas Instituições de Ensino Superior Brasileiro estudantes que 
trabalham, devido às transformações ocorridas neste contexto, considerando inclusive cada vez mais as oportunidades dos cursos noturnos e o ingresso em universidades particulares.

A tabulação e análise dos dados, considerando as informações obtidas por meio da aplicação da Escala de Autoeficácia Profissional e Decisão de carreira, elaborada por Teixeira (2005 apud GLASER 2010), foi realizada, a princípio pela obtenção da soma da pontuação obtida por cada participante, conforme as orientações propostas pelo instrumento.

Dessa forma, conforme proposto pela escala, a pontuação mínima é de 18 pontos e a máxima de 90 pontos no total. O cálculo da pontuação de cada participante evidenciou que o menor escore obtido por participante nesta pesquisa, foi de 31 , seguido por 40 , e os mais altos foram 86 e 88 pontos. A seguir na Tabela 1, apresentada a seguir, evidencia a pontuação obtida pelos participantes, por turma.

Tabela 1- Número de participantes (n), pontuação média e Desvio padrão (Dp) relativa à autoeficácia profissional e decisão de carreira por turma.

\begin{tabular}{cccc}
\hline Turmas & $\mathbf{N}$ & Média & $\boldsymbol{D p}$ \\
\hline 1000 & 26 & 67,19 & 12,53 \\
2000 & 20 & 67,00 & 14,01 \\
3000 & 16 & 68,87 & 12,57 \\
4000 & 14 & 63,35 & 10,61 \\
\hline Total & 76 & 66,78 & 12,43 \\
\hline
\end{tabular}

Fonte: Das autoras.

Observou-se que, em relação à média geral de autoeficácia dos acadêmicos participantes da pesquisa, considerando que a pontuação mínima e máxima proposta pela Escala de Autoeficácia Profissional e Decisão de carreira (TEIXEIRA, 2005 apud GLASER, 2010), pode-se sugerir que os participantes apresentaram uma pontuação intermediária entre boa e alta $(66,78)$, com base nos escores apresentados, ressaltando que a autora, na qual a escala foi utilizada não traz em seu trabalho o que seria considerada pontuação alta.

Em relação à análise por turno dos participantes, obtiveram-se os seguintes dados: os acadêmicos que estudam no período matutino (Turmas 3000 e 4000), totalizando estes 39,47\% dos participantes; obtiveram a média de 66,3. Já a pontuação média dos acadêmicos do período noturno (1000 e 2000) foi de 67,10, totalizando 60,53\% dos 
participantes. Estes dados indicam uma pequena diferença entre as médias obtidas em função dos turnos matutino e noturno. Os dados obtidos nesta pesquisa corroboram com os dados apresentados por Pereira, Zuppani e Gonçalves (2014), uma vez que os autores apontam uma pesquisa realizada com alunos de Administração, na qual os acadêmicos do turno diurno apresentaram ter crenças menores, e os do noturno demonstraram acreditar mais no seu sucesso profissional.

Guerreiro-Casanova e Polydoro (2010 apud SOUSA; BARDAGI; NUNES, 2013, p. 255) definem o constructo de autoeficácia na Formação superior como "O conjunto de crenças que um indivíduo tem sobre a sua capacidade de mobilizar recursos cognitivos e executar atos de controle sobre os eventos e demandas referentes aos aspectos compreendidos pela formação universitária". No que concerne às crenças de autoeficácia em relação aos universitários concluintes, estando estes inerentes à atuação docente, é necessário ressaltar que para Bandura (1992 apud BARDAGI; BOFF, 2010, p. 43),

[...] pessoas com baixos escores de auto-eficácia podem desenvolver comportamentos de evitação, devido às expectativas negativas sobre seu futuro desempenho. Por outro lado, sujeitos que acreditam em seu sucesso profissional tendem a assumir uma postura mais ativa no que diz respeito ao direcionamento de suas carreiras.

A atuação profissional docente requer, além de conhecimento e domínio de inúmeras estratégias pedagógicas, que o professor acredite que suas condutas sejam capazes de intervir no processo de aprendizagem de seus alunos, e acreditar em suas capacidades para tomada de decisões e ações nesse sentido (AZZI; POLYDORO; BZUNECK, 2006).

Para melhor compreensão, a Tabela 2, apresentada a seguir, evidencia a frequência (\%) de participantes e respectivos escores, por turma.

Tabela 2 - Frequência (\%) de participantes que obtiveram os respectivos escores, por turma

\begin{tabular}{|c|c|c|c|}
\hline $\begin{array}{ll}\text { Turmas } & \text { Escores } \\
\end{array}$ & 31 a 50 & 51 a 70 & 71 a 88 \\
\hline & \multicolumn{3}{|c|}{ Frequências (\%) } \\
\hline 1000 & $15,39 \%$ & $42,30 \%$ & $42,31 \%$ \\
\hline 2000 & $20 \%$ & $25 \%$ & $55 \%$ \\
\hline 3000 & $6,25 \%$ & $43,75 \%$ & $50 \%$ \\
\hline 4000 & $14,29 \%$ & $50 \%$ & $35,71 \%$ \\
\hline Total Geral & $14,47 \%$ & $39,97 \%$ & $46,05 \%$ \\
\hline
\end{tabular}

Fonte: Das autoras. 
A partir destes resultados, pode-se afirmar que escores entre 31 a 50 foram menos frequentes, o que indica que os alunos formandos do curso de Pedagogia apresentam um bom senso de autoeficácia profissional e decisão de carreira, uma vez que 86,02 apresentaram um escore acima de 51 pontos, sendo que a maioria dos alunos pesquisados apresentaram escores acima de 71 pontos.

Considerando que 1 participante da turma 1000, 4 da turma 2000 e 1 da turma 4000 possuem outra graduação, foi realizada uma análise das médias obtidas por estes alunos. Esta análise evidenciou uma média total de 65,33, quase não apresentando discrepância em relação à média geral obtida pelos participantes da pesquisa.

Ao refletir sobre a média dos acadêmicos que participam de Projetos de Pesquisa/Iniciação Científica, Disciplinas Especiais, Projetos de Extensão e de Iniciação a Docência, esta foi equivalente a 67,52 , sendo que a dos acadêmicos que não participam de nenhuma atividade acadêmica foi de 66,47 sendo levemente inferior a outra apresentada. No entanto, quando realizada a análise da média dos acadêmicos que declararam ter participado de duas atividades acadêmicas, como projeto de pesquisa/iniciação científica, estes apresentaram uma média de 69,6 sendo superior às demais.

Estudos realizados por Teixeira e Gomes (2005), Bardagi e Boff (2010) apontam que alunos que participam de atividades acadêmicas extracurriculares, como de pesquisa, apresentaram níveis mais elevados de autoeficácia. Com o objetivo de investigar variáveis possivelmente associadas à decisão de carreira entre estudantes em fim de curso universitário Teixeira e Gomes (2005), em uma pesquisa realizada com 252 estudantes de 24 cursos de uma Universidade Pública, constataram que em relação a decisão de carreira, “as variáveis exploração de informação, exploração de prática e participação em bolsa de pesquisa, contribuíram significativamente para a explicação do nível de auto-eficácia percebida" (TEIXEIRA; GOMES, 2005, p. 331), na qual ainda segundo os autores, estas variáveis têm fundamental importância para o aumento da autoeficácia, ao passo que estão relacionadas a experiências de aprendizagem que provavelmente sucedem o desenvolvimento do senso de competência profissional.

Considerando os conceitos de Decisão de Carreira e Autoeficácia Profissional, foi realizada uma análise separadamente de cada aspecto por meio da aplicação da escala. A 
pontuação mínima em relação a Decisão de Carreira equivale a 8 e a máxima 40 . 0 menor escore obtido em relação a Decisão de Carreira foi 11 e o maior escore foi 40 . Em relação à Autoeficácia Profissional, o escore mínimo é 10 e o máximo 50. A análise dos dados evidenciou que a menor pontuação obtida foi 20 e o maior escore obtido foi 50. A seguir, estão apresentados na Figura 1, a média dos escores obtidos por itens referentes à Decisão de Carreira e Autoeficácia Profissional.

Figura 1- Média dos escores dos participantes em relação à Decisão de Carreira e à Autoeficácia Profissional.

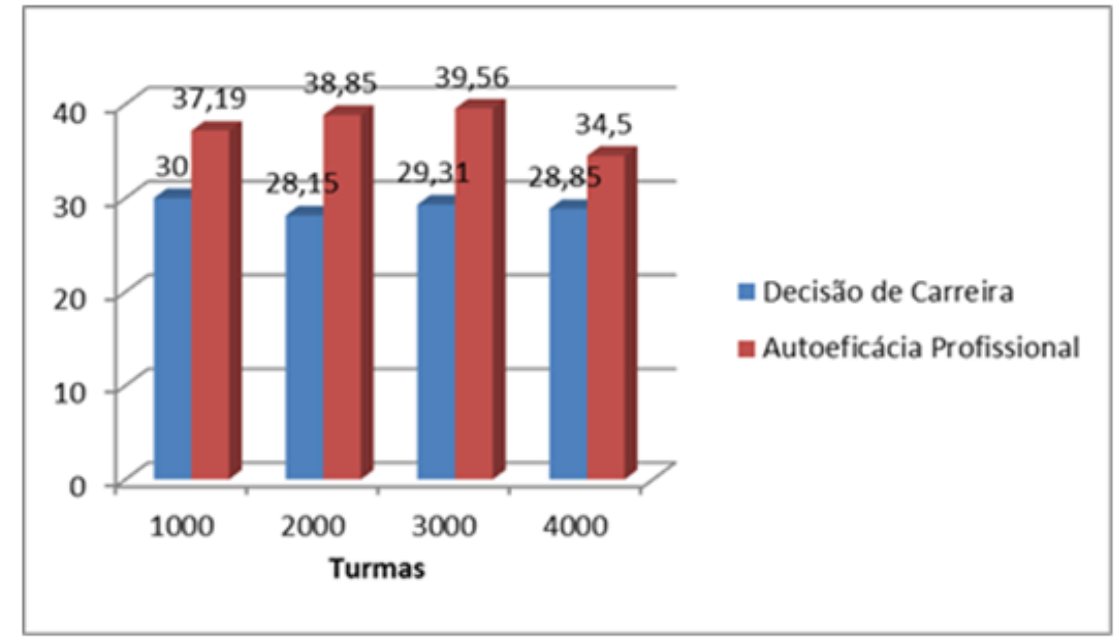

Fonte: Das autoras.

A partir destes dados, foi possível verificar que, em todas as turmas, os escores mais altos referem-se às crenças de autoeficácia em relação ao exercício profissional $(M=37,63$; $\mathrm{DP}=6,86)$ e menores escores quanto à Decisão de Carreira $(M=29,16 ; \mathrm{DP}=7,25)$. Por meio do teste não paramétrico de Kruskal Wallis, verificou-se não haver diferença significativa entre os escores de Decisão de Carreira e Autoeficácia Profissional.

Considerando que a autoeficácia profissional é definida como sendo "a crença do indivíduo em sua capacidade para desempenhar com sucesso, as atividades relativas à sua profissão." (TEIXEIRA; GOMES, 2005 apud GLASER, 2010, p. 9), de acordo com Ourique (2010, p. 51), "a auto-eficácia profissional pode vir a facilitar o processo de planejamento de carreira, representando uma fonte de motivação para que o indivíduo realize atividades exploratórias e estabeleça metas profissionais", sendo estes aspectos são essenciais neste período de transição dos acadêmicos. 
Segundo Teixeira e Gomes (2005, p. 327), a Decisão de Carreira é "entendida como a capacidade que o indivíduo tem de identificar seus interesses pela profissão, estabelecer objetivos profissionais que espera alcançar e traçar estratégias de ação coerente com essas finalidades". No entanto, a Decisão de Carreira deve estar associada à Autoeficácia Profissional, considerando que para que o sujeito sinta-se capaz de apresentar um bom desempenho em suas atividades profissionais, é necessário a elaboração de um projeto de carreira (TEIXEIRA; GOMES, 2005). Desta forma, pode-se inferir que os participantes desta pesquisa, em grande parte, demonstraram ter projetos profissionais já estabelecidos e confiança suficiente em sua capacidade para executar os mesmos.

Tendo em vista que alguns acadêmicos trabalham durante a graduação, e algumas destas atividades profissionais estão relacionadas à área na qual o acadêmico está cursando e que, outros exercem alguma atividade sem nenhuma relação ao curso, e ainda há acadêmicos que não desenvolvem nenhuma atividade profissional, pode-se verificar, a partir dos dados que os acadêmicos que atuam no contexto educacional apresentaram escores mais alto em relação à decisão de carreira e autoeficácia profissional, sugerindo que supostamente a relação teoria e prática contribua para a formação, conforme destaca Glaser (2010, p. 17):

A atividade de trabalho que se relaciona com a área de formação permite o exercício de competências necessárias à profissão, o ajustamento das expectativas e de projetos em função da realidade concreta da carreira e o engajamento precoce do aluno em relacionamentos pessoais e profissionais pertinentes ao seu contexto laboral.

Corroborando com esta afirmação, $(43,47 \%)$ dos acadêmicos que estudam no período noturno declararam exercer alguma atividade profissional relacionada à área em formação e obtiveram a média 71,40 , sendo que $(42,85 \%)$ dos acadêmicos que cursavam o período matutino na mesma situação, apresentaram a média 69,33 , ou seja, quanto mais alunos tiverem experiências e vivências com a realidade no qual irão atuar, estas podem vir a fortalecer e aumentar a crença de autoeficácia profissional.

Já os acadêmicos que não exercem atividade profissional apresentaram uma média abaixo dos que trabalham na área da educação, e por último os que exercem atividade profissional desvinculada ao campo da educação, obtiveram a menor média. Nesse sentido, Glaser (2010, p. 17) aponta que, 
[...] o trabalho desvinculado da formação, embora possa contribuir para a própria continuidade dos estudos e de forma geral aproximar o aluno do mercado de trabalho, eventualmente pode contribuir para um menor envolvimento nas atividades próprias da carreira.

Considerando que o curso de Pedagogia da Instituição pesquisada oferece a formação acadêmica para atuação na Docência, Gestão pedagógica e ainda este profissional pode atuar em espaço de educação não formal (LONDRINA, 2015), a fim de ampliar a compreensão, torna-se fundamental que os universitários concluintes apresentem alto senso de eficácia, para que possam sentir-se aptos e capazes de atuar, em qualquer destes seguimentos no qual estão habilitados a exercer profissionalmente.

Assim sendo, pode-se entender que as crenças de autoeficácia positivas frente à formação docente inicial, atuam como essencial no desenvolvimento e culminância da ação educativa, pois Pajares e Olaz (2008, p. 106), ressaltam que "fortes crenças de auto-eficácia promovem as realizações humanas e o bem-estar de incontáveis maneiras. Os indivíduos confiantes abordam tarefas difíceis como desafios a serem dominados, em vez de ameaças a serem evitadas". Nesse mesmo sentido, Vieira e Coimbra (2006) indicam que estas poderão oferecer aos acadêmicos uma importante contribuição otimista e persistente frente aos obstáculos.

\section{Considerações Finais}

A partir dos objetivos propostos por este trabalho, a análise dos resultados evidenciou que a maior parte os acadêmicos formandos do Curso de Pedagogia pesquisado apresentaram um nível moderado de crença de autoeficácia em relação ao exercício profissional e um nível mais elevado por participantes que participaram de atividades de pesquisa, iniciação à docência. Estes resultados evidenciam que a participação nestas atividades acadêmicas pode contribuir como fonte para o aumento das crenças de autoeficácia, mais precisamente a considerada experiência de domínio. Da mesma forma, participantes que declararam trabalhar no campo da educação durante a graduação, apresentaram ter mais confiança e sentiram-se mais preparados em relação aos demais, que atuam em seguimentos distintos ou não trabalhavam. Esta análise dá indicativos de que a relação teoria e prática contribuem de maneira positiva e significativa, para a formação, promovendo melhor desenvolvimento do acadêmico em sua atuação. 
De forma geral, os resultados evidenciaram que os acadêmicos do curso de Pedagogia, em sua grande maioria se sentem preparados em relação aos conhecimentos profissionais e habilidades, confiantes em sua capacidade, e já estabeleceram metas e objetivos diante da futura carreira profissional.

Em relação aos turnos matutino e noturno, obteve-se uma pequena diferença entre as médias, no qual podemos considerar que os acadêmicos do período noturno apresentaram um nível levemente maior em relação a crença de autoeficácia frente ao exercício profissional, ou seja, se sentiam mais confiantes em relação aos participantes do curso matutino. Este resultado pode estar associado ao fato de que, mais da metade dos acadêmicos que estudam no período noturno desempenha atividade profissional durante o dia, em sua maioria, associada ao contexto educacional, experiência esta que pode ter contribuído para o aumento das crenças de autoeficácia, uma vez que exige requisitos, qualificação, aquisição de conceitos, conhecimentos, habilidades, consideradas fundamentais para a construção e formação dos mesmos.

Considerando a importância e a influência que as crenças de autoeficácia exercem sobre o indivíduo, nos seus pensamentos, ações e em seu comportamento, as interações estabelecidas na Universidade, as experiências no contexto educacional e seus resultados, exercem papel preponderante na formação acadêmica e na formação das crenças dos indivíduos durante a graduação.

Sendo assim, respaldada nos estudos já realizados e na Teoria Social Cognitiva proposta por Bandura, em relação à importância que as crenças de autoeficácia possuem frente à atuação docente, é essencial que cada vez mais sejam propostas e efetivadas nos cursos de formação superior, medidas que contribuam para reforçar positivamente tais crenças, que garantam ao futuro docente, condições para que cada vez mais se sintam capazes e confiantes frente a sua ação docente e evidentemente no contexto profissional.

Nesse sentido, o incentivo por parte dos docentes e da Coordenação Pedagógica, a fim de que os alunos participem de atividades relacionadas à pesquisa e extensão, inclusive já nos primeiros anos de graduação, bem como a orientação e indicação de que os alunos exerçam atividades profissionais relacionadas à Educação poderá contribuir cada vez mais, para que estes possam através da teoria e da prática, desempenhar ações e reflexões fundamentais para a formação docente, tornando-se alunos altamente capacitados e 
confiantes em relação a sua atuação profissional. Além disso, o professor Universitário também pode utilizar do encorajamento verbal, a fim de contribuir para a autoeficácia na formação superior.

Existem atualmente muitos desafios e barreiras no contexto educacional, de modo que o nível positivo da crença de autoeficácia contribuirá para melhores desdobramentos desta ação, consequentemente refletindo na formação e aprendizado dos alunos, pois é preciso acreditar que se é capaz de fazer diferente e cada vez melhor, para não se deixar levar na mesmice e no tradicionalismo, que permeia o contexto educativo. Bem como, ressaltando aqui a importância e a contribuição de incentivar e acreditar na capacidade dos acadêmicos em formação, pois estes aspectos agregam no aumento positivo das crenças de eficácia do mesmo frente aos desafios e adversidades que surgem ao longo de todo percurso, de modo que este perceba que é capaz e almeje novas e maiores conquistas profissionais e acadêmicas.

Portanto, é preciso cada vez mais acreditar na capacidade dos acadêmicos e futuros profissionais da educação, como sendo capazes de proporcionar, por meio de sua atuação, uma educação significativa e de qualidade para todos.

\section{Referências}

AZZI, Roberta Gurgel; POLYDORO, Soely Aparecida Jorge. Auto-eficácia proposta por Albert Bandura: algumas discussões. In: AZZI, Roberta Gurgel; POLYDORO, Soely Aparecida Jorge (Org.). Auto-eficácia em diferentes contextos. Campinas: Alínea, 2006. p. 9-23.

AZZI, Roberta Gurgel; POLYDORO, Soely Aparecida Jorge; BZUNECK, José Aloyseo. Considerações sobre a auto-eficácia docente. In: AZZI, Roberta Gurgel; POLYDORO, Soely Aparecida Jorge (Org.). Auto-eficácia em diferentes contextos. Campinas: Alínea, 2006. p. 149-159.

BANDURA, Albert. O sistema self no determinismo recíproco. In: BANDURA, Albert; AZZI, Roberta Gurgel; POLYDORO, Soely. Teoria social cognitiva: conceitos básicos. Porto Alegre: Artmed, 2008. p. 43-67.

BARDAGI, Marucia Patta; BOFF, Raquel de Mello. Autoconceito, auto-eficácia profissional e comportamento exploratório em universitários concluintes. Avaliação, Sorocaba, v. 15, n. 1, mar. 2010. Disponível em: <http://www.scielo.br/pdf/aval/ v15n1/v15n1a03.pdf>. Acesso em: 7 jan. 2015.

BZUNECK, José Aloyseo. As crenças de auto-eficácia e o seu papel na motivação do aluno. 
In: BORUCHOVITCH, Evely; BZUNECK, José Aloyseo (Org.). A motivação do aluno: contribuições da psicologia contemporânea. 3. ed. Rio de Janeiro: Vozes, 2001. p. 116-133.

CERUTTI, Fernanda et al. Autoeficácia entre estudantes universitários ingressantes e veteranos de dois cursos. Ciências \& Cognição, Rio de Janeiro, v. 16, n. 3, p. 57-65, 2011. Disponível em: <http://www.cienciasecognicao.org/revista/ index.php/cec/article/view/745/514>. Acesso em: 7 jan. 2014.

FERREIRA, Marco Antonio Cabral. A influência da auto-eficácia e da ansiedade em jogadores de futebol. 2008. Dissertação (Mestrado Departamento de Educação Física) Universidade Federal do Paraná, Curitiba, 2008.

FONTES, Arlete Portella; AZZI, Roberta Gurgel. Crenças de autoeficácia e resiliência: apontamentos da literatura sociocognitiva. Estudos de Psicologia, Campinas, v. 29, n. 1, p. 105-114. jan./mar. 2012.

GHEDIN, Evandro; LEITE, Yoshie Ussami Ferrari; ALMEIDA, Maria Isabel de. Formação de professores: caminhos e descaminhos da prática. Brasília: Liber Livro, 2008.

GLASER, Sheila Lauffer. Relações entre habilidades sociais, auto-eficácia e decisão de carreira em universitários em final de curso. 2010. 32 f. Monografia (Especialização em Psicologia Clínica) - Instituto de Psicologia, Universidade Federal do Rio Grande do Sul, Porto Alegre, 2010.

GUERREIRO-CASANOVA, Daniela Couto; POLYDORO, Soely Aparecida Jorge. Autoeficácia na formação superior: percepções durante o primeiro ano de graduação. Psicologia, Ciência e Profissão, Campinas, v. 31, n. 1, p. 50-65, 2011. Disponível em:

<http://www.scielo.br/pdf/pcp/v31n1/v31n1a06.pdf>. Acesso em: 1 dez. 2014.

IAOCHITE, Roberto Tadeu et al. Autoeficácia docente, satisfação, e disposição para continuar na docência por professores de educação física. Revista Brasileira de Ciência do Esporte, Florianópolis, v. 33, n. 4, p. 825-839, out./dez. 2011.

IMBERNÓN, Francisco. Formação docente profissional: formar-se para a mudança e a incerteza. 3. ed. São Paulo, Cortez, 2002.

LONDRINA. Universidade Estadual de Londrina. Centro de Educação Comunicação e Artes. Curso de pedagogia. Disponível em: <http://www.uel.br/ceca/pedagogia/> Acesso em: 3 mar. 2015.

MOGNON, Jocemara Ferreira; SANTOS, Acácia Aparecida Angeli. Vida acadêmica e exploração vocacional em universitários formandos: relações e diferenças. Estudos $e$ Pesquisas em Psicologia, Rio de Janeiro, v. 14, n. 1, p. 89-106, 2014. Disponível em: <http://www.e-publicacoes.uerj.br/index.php/ revispsi/article/view/10481/8253 > Acesso em: 9 jan. 2015. 
OURIQUE, Luciana Rubensan. Auto-eficácia e personalidade no planejamento de carreira de universitários. 2010. 84 f. Dissertação (Mestrado em Psicologia) - Universidade Federal do Rio Grande do Sul, Porto Alegre, 2010.

PAJARES, Frank; OLAZ, Fabian. Teoria social cognitiva e auto-eficácia uma visão geral. In: BANDURA, Albert; AZZi, Roberta Gurgel; POLYDORO, Soely. Teoria social cognitiva: conceitos básicos. Porto alegre: Artmed, 2008. p. 97-114.

PEREIRA, Ana Lúcia; ZUPPANI, Tatiani dos Santos; GONÇALVES, Marcelo Neves. Crenças de autoeficácia e carreira de estudantes de administração. Atos de Pesquisa em Educação, Blumenau, v. 9, n. 2, p. 535-547, maio/ago. 2014. Disponível em:

<http://proxy.furb.br/ojs/index.php/atosdepesquisa/ article/view/3896/2758>. Acesso em: 6 mar. 2015.

ROCHA, Márcia Santos. A auto-eficácia docente no ensino superior. 2009. Tese (Doutorado em Psicologia Educacional) - Universidade Estadual de Campinas, Campinas, 2009.

SILVA, Afonsa Janaína da; IAOCHITE, Roberto Tadeu; AZZI, Roberta Gurgel. Crenças de autoeficácia de licenciandos em educação física. Motriz: Revista de Educação Física, Rio Claro, v. 16, n. 4, p. 942-949, out./dez. 2010.

SOUSA, Heloiza de; BARDAGI, Marucia Patta; NUNES, Carlos Henrique Sancineto da Silva. Autoeficácia na formação superior e vivências de universitários cotistas e não cotistas. Avaliação Psicológica, Florianópolis, v. 12, n. 2, p. 253-261, 2013.

SOUZA, Liliane Ferreira Neves Inglez; BRITO, Márcia Regina Ferreira. Crenças de autoeficácia, autoconceito e desempenho em matemática. Estudos de Psicologia, Campinas, v. 25, n. 2, p. 193-201, 2008.

TEIXEIRA, Marco Antônio Pereira; GOMES, William B. Decisão de carreira entre universitários em fim de curso universitário. Psicologia: Teoria e Pesquisa, Santa Maria, v. 21, n. 3, p. 327-334, set./dez. 2005.

VIEIRA, Diana; COIMBRA, Joaquim Luís. A auto-eficácia na transição para o trabalho. In: AZZI, Roberta Gurgel; POLYDORO, Soely Aparecida Jorge (Org.). Auto-eficácia em diferentes contextos. Campinas: Alínea, 2006. p. 25-58. 